\title{
EDITORIAL REMARKS
}

Saludos!

Welcome to Volume 20 of Ancient Mesoamerica. In celebrating our $20^{\text {th }}$ anniversary, Mesoamericanists will recognize the auspicious significance of reaching our first katun. Whereas auto-sacrifice is not on the agenda, we would like to call your attention to some of the developments at the journal.

Ancient Mesoamerica has been selected for coverage in the Thomson-Reuters Arts and Humanities Citation Index (ISI) and also the Current Contents/Arts and Humanities. This is a prestigious honor reflecting the journal's place among the "elite". It also means that articles will be indexed and abstracted as a resource for the scientific and scholarly research community. This level of recognition was identified as a goal during last year's Editorial Board meeting, and we are grateful to Board members for their support in attaining this status.

Daniel Pearce, general editor for the Humanities and Social Sciences journals at Cambridge University Press, reports that Ancient Mesoamerica's circulation has never been higher. Subscriptions are up in all areas, including twelve new institutional subscriptions from South America. Over 150 new institutions are receiving consortia subscriptions. He concludes by saying that despite the economic downturn, Ancient Mesoamerica is "in a very healthy state."

Another reflection of the journal's health is the volume of submissions, which at this point is unprecedented. We currently have more than fifty manuscripts in various stages of production; considering each issue contains about ten articles this indicates enough content to last until 2011. While this may be frustrating to authors planning to submit new manuscripts, it also signifies that we can be more selective during the review process, and even more meticulous during the production process.

In addition to these organizational achievements, Ancient Mesoamerica is also developing new programs to better serve the scholarly community. With this issue, we are beginning to publish select color images. William Ringle's article on the Upper Temple of the Jaguars from Chichen Itza is greatly enhanced by the inclusion of color figures of the murals themselves. While this will remain an exceptional option, we look forward to future use of color imagery.

Another enhancement will be the launch of the Ancient Mesoamerica web page later this fall. The web page is intended to offer a variety of features to connect Mesoamerican scholars more effectively. For example, News and Events will feature announcements of upcoming events, exhibitions, and important discoveries, while Links will provide contact information to different web pages of interest. In an attempt to make the web page more interactive, Comments will offer an opportunity to discuss recent contributions in a professional manner. Tell Tales is a place to send 'tales from the field', with the potential of virtually virtual updates, including images. The Ceramoteca can house type collections of different artifact classes for comparison without the need to lug your reference library into the field, as well as being a place to post "problem sherds" for possible identification. These are but a few of the features of the new web page-we invite you to contribute! Contact us at ancientmeso@cambridge.org for more information.

Finally, and in keeping with our $20^{\text {th }}$ anniversary theme, the Fall 2009 issue will celebrate our period ending with a special katun issue. We have invited prominent scholars to write their own state-of-the-art essays on their particular specialties. Their instructions were to briefly describe how we got to this point, what the current debates are, and especially where the field might go during the next 20 years. Included will be a cumulative bibliography, which will also be posted on the web page for continual development.

With these developments Ancient Mesoamerica is preparing for our next 20 years, adapting to new technologies while attempting to better serve our readers. Mesoamerica remains a dynamic field, and it is our goal to reflect the diversity of scholarly involvement.

Geoffrey G. MCCAFFERTy WILliam R. FOWLER 